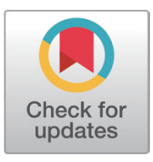

Received: Oct 6, 2021

Revised: Oct 12, 2021

Accepted: Oct 13, 2021

*Corresponding author

Ju Lan Chun

National Institute of Animal Science,

Rural Development Administration,

Wanju 55365, Korea.

Tel: +82-63-238-7053

E-mail: julanchun@korea.kr

Copyright () 2021 Korean Society of Animal Sciences and Technology.

This is an Open Access article distributed under the terms of the Creative Commons Attribution

Non-Commercial License (http:// creativecommons.org/licenses/bync/4.0/) which permits unrestricted non-commercial use, distribution, and reproduction in any medium, provided the original work is properly cited.

ORCID

Ki Hyun Kim

https://orcid.org/0000-0002-9834-2126

Kangmin Seo

https://orcid.org/0000-0001-6152-8536

Hyun-Woo Cho

https://orcid.org/0000-0002-3620-9952

Jung-Hwan Jeon

https://orcid.org/0000-0001-9725-547X

Chan Ho Kim

https://orcid.org/0000-0003-2121-5249

Jiyeon Jung

https://orcid.org/0000-0002-4693-8323

Ju Lan Chun

https://orcid.org/0000-0002-4618-586X

Competing interests

No potential conflict of interest relevant to this article was reported.

Funding sources

This work was carried out with the support of the Cooperative Research

Program of Center for Companion

\section{Age-related digestibility of nutrients depending on the moisture content in aged dogs}

\author{
Ki Hyun Kim, Kangmin Seo, Hyun-Woo Cho, Jung-Hwan Jeon, \\ Chan Ho Kim, Jiyeon Jung and Ju Lan Chun* \\ National Institute of Animal Science, Rural Development Administration, Wanju 55365, Korea
}

\begin{abstract}
Digestibility of pet food can affect the health of dog, especially of aged animals. To maintain the health of dogs in an overall good status it is necessary to provide nutritionally balanced food. For example, the digestibility of dogs was known to be decreased along aging. In addition, losing teethes is an often event in aged dogs that could induce a problem to eat a large size dry pet food. Nonetheless, few detailed information is available on the most suited feeding for aged dogs. As part of the nutritional study of food for aged dogs, in this study, we tested whether food type impacts on digestibility on adult versus senior dogs. The methodology to measure the digestibility of nutrients was chosen the index method using chromium oxide. Dogs were fed the same commercial dry or wet diets, which were supplemented with $0.5 \%$ chromium oxide. The wet food was prepared by adding twice volume of water in the dry food prior to incubated overnight (14-16 hours) at room temperature. After five days, their feces were collected up to a total weight of $>200 \mathrm{~g}$ which was the amount to analyze undigested nutrients in feces as 3 repeats. In the apparent total tract digestibility analysis of the experimental breed, no difference in the digestibility of crude protein, crude fat, crude fiber, ash, and energy was observed regarding the moisture content of the food. Noteworthy, the digestibility of nitrogen free extract was significantly increased in senior dogs fed dry dog food compared with adult dogs fed the same diet, whereas no difference was observed between senior and adult dogs fed wet food. The small breed dogs showed similar results to the experimental breed dogs. However, the digestibility of crude fat was additionally affected by age and food type unlike the experimental breed dogs. This finding suggests that the food moisture content affects the digestibility of nutrients in dogs with aging. Hence, it may be helpful to determine the nutrient contents in foods for senior dogs depending on the food type.
\end{abstract}

Keywords: Aging, Digestibility, Dog, Moisture content, Nitrogen free extract

\section{INTRODUCTION}

In recent years, companion animals, such as dogs and cats, have become important elements of the society; concomitantly, the premium pet food industry has significantly increased with the growing interest of the owners on the well-fare and overall healthy life of their companion animals. With aging, dogs experience diminished physical capacity and metabolic alternations, which ultimately result in 
Animal Research (Project No. PJ01476701), Rural Development Administration, Korea.

Acknowledgements

This study was supported by the 2021 RDA

Fellowship Program of the National Institute of Animal Science, Rural Development Administration, Korea.

Availability of data and material Upon reasonable request, the datasets of this study can be available from the corresponding author.

Authors' contributions

Conceptualization: Kim KH, Chun JL.

Data curation: Chun JL.

Formal analysis: Seo K, Cho HW.

Methodology: Kim KH, Jung J.

Validation: Jeon JW, Kim $\mathrm{CH}$.

Writing - original draft: Kim KH, Chun JL.

Writing -review \& editing: Kim KH, Seo K,

Cho HW, Jeon JW, Kim CH, Jung J, Chun JL.

Ethics approval and consent to participate The animal study design was approved by IACUC review board in National Institute of Animal Science, Korea(Approval Number: NIAS-2020-438). demands of specific senior health care practices, including senior pet foods for weight control, antiaging, or for preventing age-related diseases [1,2]. Therefore, currently, more attention has been granted to nutritionally balanced pet foods that can maintain good health and delay the onset of diseases in aged dogs [3].

Digestibility of nutrients is a crucial feature that allows dogs obtain the essential nutritional and energy requirements. Dogs need a minimum amount of energy to support their biological equilibrium, including a healthy body size, composition, and temperature [4]. It is known that aged dogs have a significantly decreased maintenance energy [5,6]. According to previous studies with different dog breeds, the energy requirement in aged dogs declines by approximately $20 \%$ compared with that in adult dogs $[7,8]$. With aging, physiological and metabolic changes, such as like diminished lean body mass, immune response, and enzymatic activity, are related with a deteriorated capacity for maintaining the energy requirements [1].

The Association of American Feed Control Officials (AFFCO) suggests nutritional guidelines only for 'Reproduction and Growth' and 'Adult Maintenance,' which have been commonly used to produce pet foods that are sold by pet food companies. Noteworthy, it is important to ensure adequate digestibility in dogs feed pet foods for maintaining an overall good health status [3,9]; however, there is no defined nutritional guideline for aged dogs. For example, to help food digestion in aged dogs, the owners often provide them wet foods (canned or pouched) regardless of the existence of any disease. In addition, dogs preferred moist and semi-moist diets compared to dried food [10]. Moreover, there is not enough information about the possible effect of moisture content on the nutritional profile of wet and dry pet foods.

As growing the pet food market, the type of dog foods become diverse. The dry food and wet food refer the most common types of pet food. For aged dogs, the wet food type could be easier to eat and palatable diets regarding their diminished physical conditions and reduced appetize. However, there is not enough information of dry and wet food in terms of nutritional digestibility. This study aimed to evaluate and compare the digestibility of nutrients in commercial dog foods depending on the moisture content in adult and aged dogs. The collected information is expected to provide some reference for the optimal nutrient composition of pet foods specific for aged dogs.

\section{MATERIALS AND METHODS}

\section{Animals}

The animal experimental protocols used in this study were approved by the Institutional Animal Care and Use Committee of the National Institute of Animal Science (NIAS), Korea (Approval number: NIAS-220-438). Twenty-four adult beagles (aged 2 years), nine senior beagles (aged 10 years), 26 small breed senior dogs (aged 10 years), and six small breed adult dogs (aged 4 years) were used (Table 1). Each one was individually housed, with constant temperature $\left(22^{\circ} \mathrm{C}-24^{\circ} \mathrm{C}\right)$ and humidity (60\%-80\%). The dogs were exercised once a day for approximately $3-4 \mathrm{~h}$ in an outside playground. NIAS veterinarians monitored the dogs in need.

\section{Diets}

Dogs were fed the same commercial diets, in either dried or wet conditions, which was provided as a daily meal for at least one year. Nutrient composition and energy contents of the diet are shown in Table 2. The dried pet food consisted of an extruded type. The wet food was prepared by adding water to the dried food in a 2:1 ratio (w/w), which was then incubated overnight (14-16 h) at room temperature. The diet which dogs were fed contained $0.5 \%$ chromium oxide This study was performed by crossover experiment design. Half of the senior and adult dogs were given dried or 
Table 1. Age, weight and feeding information of the dogs used in the study

\begin{tabular}{|c|c|c|c|c|c|c|c|}
\hline Groups & Breeds & Number & $\begin{array}{c}\text { Age } \\
\text { (year) }\end{array}$ & $\begin{array}{l}\text { BW } \\
(\mathrm{kg})\end{array}$ & $\underset{(\mathrm{kg})}{\mathrm{mBW}}$ & $\begin{array}{l}\text { Energy requirement } \\
\text { (kcal) }\end{array}$ & $\begin{array}{l}\text { Feeding amount } \\
\text { (g) }\end{array}$ \\
\hline \multicolumn{8}{|c|}{ Experimental breed } \\
\hline Senior & Beagle & 9 & 11 & $14.3 \pm 3.5$ & $10.8 \pm 2.6$ & $1,419.0 \pm 347.5$ & $235.6 \pm 45.6$ \\
\hline Adult & Beagle & 24 & 4 & $11.8 \pm 2.3$ & $8.8 \pm 1.7$ & $1,164.3 \pm 222.7$ & $203.5 \pm 28.7$ \\
\hline \multicolumn{8}{|l|}{ Small breeds } \\
\hline \multirow[t]{2}{*}{ Senior } & Poodle & 10 & 11 & $3.6 \pm 1.1$ & $2.6 \pm 0.6$ & $341.2 \pm 78.5$ & $83.2 \pm 19.1$ \\
\hline & Schnauzer & 7 & 11 & $6.4 \pm 0.8$ & $4 \pm 0.4$ & $527.8 \pm 50.1$ & $128.7 \pm 12.2$ \\
\hline \multirow[t]{3}{*}{ Adult } & Pomeranian & 2 & 5 & 4.5 & 2.5 & 330.5 & 80.6 \\
\hline & Yorkshire terrier & 2 & 5 & 3.0 & 1.8 & 248.1 & 60.5 \\
\hline & Shi-Tzu & 2 & 5 & 5.5 & 3.8 & 501.1 & 122.2 \\
\hline
\end{tabular}

BW, body weight; $\mathrm{mBW}$, metabolic body weight.

Table 2. Nutrient composition of the pet food fed dogs in the study (wet-base)

\begin{tabular}{lc}
\hline \multicolumn{1}{c}{ Items } & Experimental diet \\
\hline Moisture (\%) & 5.6 \\
Crude protein (\%) & 33.2 \\
Ether extract (\%) & 20.4 \\
Crude fiber (\%) & 8.0 \\
Crude ash (\%) & 9.0 \\
Nitrogen free extract (\%) & 23.8 \\
Metabolic energy (kcal/kg) & $4,760.5$ \\
\hline
\end{tabular}

wet food for five days, and after the first feeding test the dogs were switched groups and were feed the other type of food (either wet or dried food, respectively). The feeding amount was determined based on the metabolic energy requirement according to the recommendation of AFFCO (metabolizable energy $[\mathrm{ME}]$, kcal/day $132 \times$ body weight $[\mathrm{BW}]_{0.75} \mathrm{~kg}$ ).

\section{Apparent total track digestibility (ATTD)}

Dogs were fed based on the energy requirement calculated by the metabolic body weight according to the recommendation of AFFCO. The diet which dogs were fed contained 0.5\% Chromium oxide. After receiving the diet for five days, feces from each dog were collected up until the total weight reached $>200 \mathrm{~g}$. The nutrients and chromium oxide $\left(\mathrm{Cr}_{2} \mathrm{O}_{3}\right)$ analysis were performed by the standard protocol according to AOAC. Then, ATTD was determined using the index method, by calculating the concentration of $\mathrm{Cr}_{2} \mathrm{O}_{3}$ in the feces according to the following equation:

$$
\text { Digestibility }(\%)=100-\left\{\left(\frac{\text { Chromium oxide (input) } \times \text { Fecal nutrient (output) }}{\text { Chromium oxide }(\text { output }) \times \text { Fecal nutrient (input) }}\right) \times 100\right\}
$$

\section{Statistical analysis}

All statistical analysis was performed using SPSS version 17.0 (SPSS, Chicago, IL, USA). Significant differences in digestibility for nutrients and energy in the beagle breed were analyzed using two-way (foody type and age) analysis of variance (ANOVA) of the procedures for general linear model (PROC GLM). In case of the small breed group, because it comprised six different breeds, the significant differences in digestibility for nutrients and energy were analyzed using 
two-way analysis of covariance (ANCOVA) of the PROC GLM by treating the breed factor as a covariate. Differences were considered statistically significant when $p<0.05$.

\section{RESULTS AND DISCUSSION}

The average age of companion dogs has been increasing in recent years. To maintain good health and prolong longevity of dogs, owners have become increasingly concerned with the food they give them. According to the report of global pet food sales market [11], dried pet food rank first among different pet food types. However, aged dogs are preferably fed soft diets, such as wet foods (canned or pouched) for an easier digestion. In this study, we investigated whether apparent digestibility in dogs with different ages is affected by moisture content in the food. The moisture contents of dried and wet food herein used were of 5\%-7\% and approximately $70 \%$, respectively, which were similar to that comprised in commercial extruded and (canned or pouched) wet foods. Moreover, the dried and wet foods contained the same nutrients, except water, thereby minimizing the effect of untargeted nutrients within the dog food. To investigate the possible difference of experimental and pet dogs, dogs used in the study were Beagles, which is a commonly used experimental dog breed, and small breeds, which were used as reference to the most popular dog breeds (Maltese and Poodle) in South Korea. For ANCOVA analysis the "small breeds experiment" was considered as a covariate. In the result of ANCOVA we got 0.759, 0.985, 0.981, 0.947, 0.288, 0.796, 0.890, 0.814 for the digestibility of dry matter (DM), crude protein, crude fat, crude fiver, ash, nitrogen free extract (NFE), organic matter (OM), and energy (unpublished data). There was no significant effect of the breed in the small breed experiment.

Based on ATTD results, no significant interaction between food type and age was observed (Table 3). However, age was related with the digestibility of NFE, which consist of soluble carbohydrates including starch and sugar. Indeed, NFE digestibility was significantly higher in senior dogs fed dried food as compared with adult dogs, but no difference was noted among dogs fed wet food. Noteworthy, the digestibility of amino acids was not affected by the food type or age of the animals (Table 4). Therefore, NFE digestibility in the experimental breed dogs may be related with the moisture content of the food. Crude protein, crude fat, and NFE are the main energy sources in dog foods [9]. Similar to humans, dogs are able to use carbohydrates as energy for their body by breaking down these complex molecules into simple sugar shapes [12,13]. As NFE digestibility was high in senior dogs fed dried food, adjustment of the total energy content

Table 3. Apparent total tract digestibility of main nutrients in the experimental breed dog (beagle) fed dried and wet foods

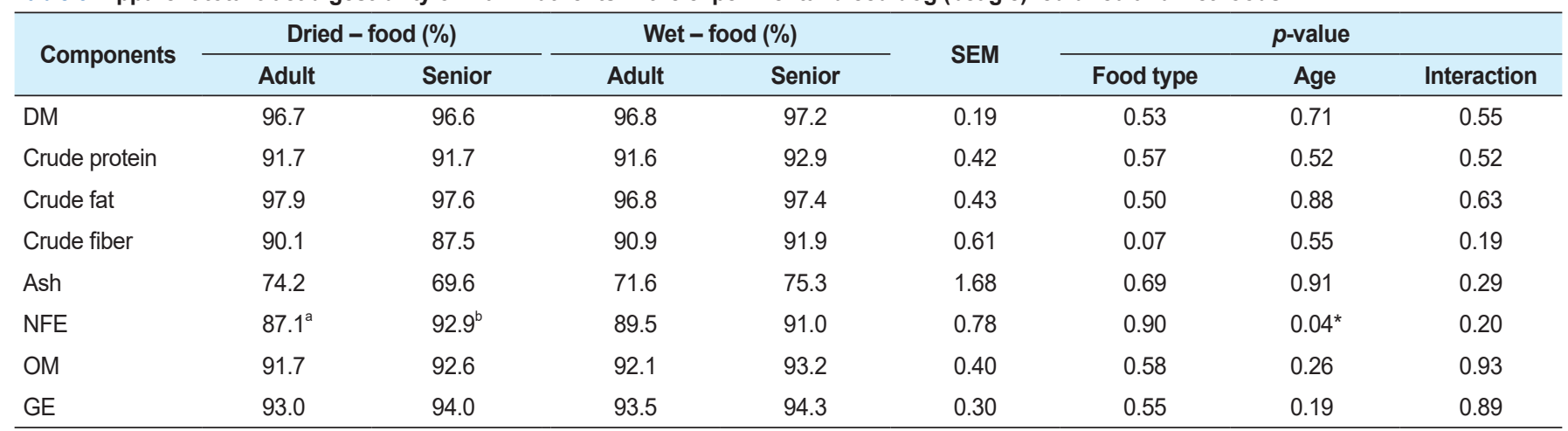

a,b Means with different superscripts within the rows of dried or wet food are significantly different $(p<0.05)$.

${ }^{*} p<0.05$.

$\mathrm{DM}$, dry matter; NFE, nitrogen free extract; OM, organic matter; GE, gross energy. 
Table 4. Apparent total tract digestibility of amino acids in the experimental breed dogs (beagle) fed dried and wet foods

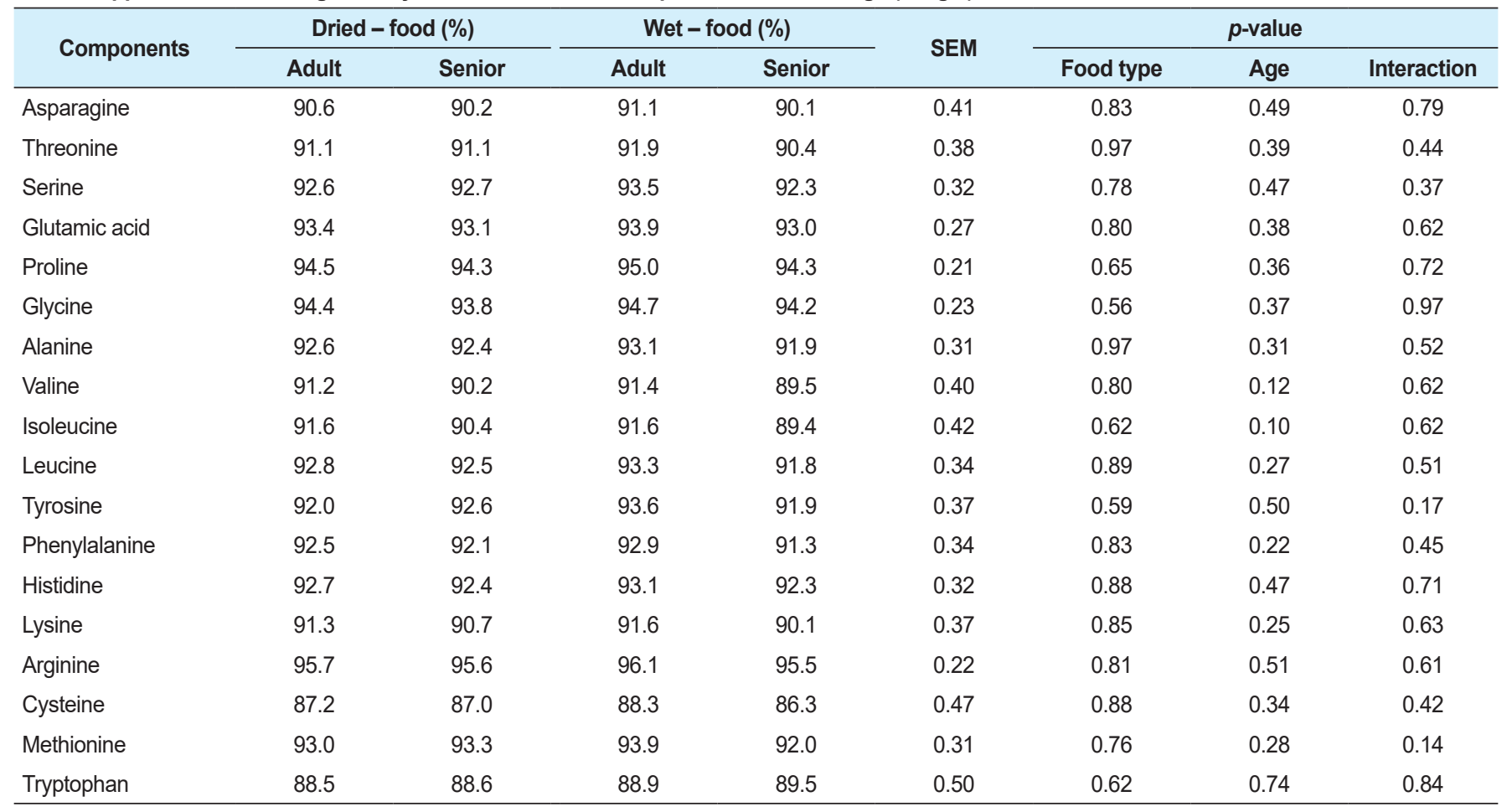

(especially concerning carbohydrates) based on the moisture content in dog food and the age of the animal could be beneficial.

Within popular small breed dogs, ATTP data showed that crude fat was significantly correlated with food type and age (Table 5). However, no significant interaction between food type and aging was observed. When grouping the dogs according to dried or wet food feeding, a significant difference in the digestibility of NFE between adult and senior dogs in dried food feeding group $(p<0.05)$ was noticeable, similarly to that noted in the experimental breed dogs (Table 5). Moreover, no significant differences in digestibility were observed between adult and senior dogs in wet food feeding group, and the ATTP data regarding amino acids were also not different among the dogs (Table 6). Taken together, these results indicate that the digestibility of crude fat in small breed dogs

Table 5. Apparent total tract digestibility of main nutrients in the small breed dogs fed dried and wet foods

\begin{tabular}{|c|c|c|c|c|c|c|c|c|}
\hline \multirow{2}{*}{ Components } & \multicolumn{2}{|c|}{ Dried - food (\%) } & \multicolumn{2}{|c|}{ Wet - food (\%) } & \multirow{2}{*}{ SEM } & \multicolumn{3}{|c|}{$p$-value } \\
\hline & Adult & Senior & Adult & Senior & & Food type & Age & Interaction \\
\hline DM & $94.3^{\mathrm{a}}$ & $95.5^{b}$ & 95.9 & 95.7 & 0.18 & 0.28 & 0.34 & 0.49 \\
\hline Crude fat & 95.6 & 96.8 & 95.6 & 96.2 & 0.18 & $0.05^{*}$ & $0.02^{*}$ & 0.50 \\
\hline Crude fiber & 63.0 & 59.9 & 56.3 & 59.8 & 1.70 & 0.31 & 0.78 & 0.32 \\
\hline OM & 89.4 & 90.7 & 91.1 & 90.7 & 0.30 & 0.65 & 0.88 & 0.66 \\
\hline GE & 90.3 & 91.1 & 91.4 & 91.0 & 0.30 & 0.85 & 0.78 & 0.70 \\
\hline
\end{tabular}

$\overline{a, b}$ Means with different superscripts within the rows of dried or wet food are significantly different $(p<0.05)$.

${ }^{*} p<0.05$.

$\mathrm{DM}$, dry matter; NFE, nitrogen free extract; OM, organic matter; GE, gross energy. 
Table 6. Apparent total tract digestibility of amino acids in the small breed dogs fed dried and wet foods

\begin{tabular}{|c|c|c|c|c|c|c|c|c|}
\hline \multirow{2}{*}{ Components } & \multicolumn{2}{|c|}{ Dried - food (\%) } & \multicolumn{2}{|c|}{ Wet - food (\%) } & \multirow{2}{*}{ SEM } & \multicolumn{3}{|c|}{$p$-value } \\
\hline & Adult & Senior & Adult & Senior & & Food type & Age & Interaction \\
\hline Asparagine & 90.8 & 90.5 & 90.1 & 90.9 & 0.41 & 0.88 & 0.82 & 0.64 \\
\hline Threonine & 91.3 & 91.1 & 90.4 & 91.7 & 0.38 & 0.86 & 0.56 & 0.46 \\
\hline Serine & 92.7 & 92.6 & 92.3 & 93.4 & 0.32 & 0.82 & 0.54 & 0.46 \\
\hline Glutamic acid & 93.4 & 93.4 & 93.0 & 93.7 & 0.27 & 0.96 & 0.61 & 0.62 \\
\hline Proline & 94.4 & 94.5 & 94.3 & 94.8 & 0.21 & 0.85 & 0.58 & 0.73 \\
\hline Glycine & 94.2 & 94.3 & 94.3 & 94.5 & 0.23 & 0.82 & 0.74 & 0.93 \\
\hline Alanine & 92.5 & 92.7 & 92.0 & 92.9 & 0.31 & 0.82 & 0.49 & 0.66 \\
\hline Valine & 90.8 & 91.2 & 89.3 & 91.2 & 0.40 & 0.48 & 0.30 & 0.48 \\
\hline Isoleucine & 91.1 & 91.5 & 89.3 & 91.3 & 0.42 & 0.35 & 0.25 & 0.47 \\
\hline Leucine & 92.8 & 92.9 & 91.7 & 93.1 & 0.34 & 0.62 & 0.44 & 0.45 \\
\hline Tyrosine & 92.8 & 92.1 & 91.9 & 93.5 & 0.37 & 0.75 & 0.65 & 0.23 \\
\hline Phenylalanine & 92.5 & 92.5 & 91.2 & 92.7 & 0.34 & 0.55 & 0.41 & 0.40 \\
\hline Histidine & 92.9 & 92.7 & 92.2 & 92.9 & 0.32 & 0.80 & 0.75 & 0.58 \\
\hline Lysine & 91.2 & 91.3 & 90.1 & 91.3 & 0.37 & 0.58 & 0.50 & 0.55 \\
\hline Arginine & 96.1 & 95.7 & 95.4 & 96.0 & 0.22 & 0.73 & 0.89 & 0.40 \\
\hline Cysteine & 86.2 & 87.4 & 86.5 & 88.1 & 0.47 & 0.67 & 0.25 & 0.85 \\
\hline Methionine & 92.6 & 93.2 & 91.9 & 93.8 & 0.31 & 0.94 & 0.12 & 0.43 \\
\hline Tryptophan & 89.3 & 88.5 & 89.5 & 88.8 & 0.50 & 0.84 & 0.55 & 0.98 \\
\hline
\end{tabular}

may be related with the moisture content in the food and with aging. In addition, NFE digestibility can be improved in senior dogs when fed dried dog foods, which has low moisture content. Hence, control of the total energy intake based on crude fat and carbohydrate contents monitoring in dog food may be beneficial for aging small breed dogs.

Dogs are omnivores that eat meat and plants to obtain the essential nutrients [14]. Along with proteins and fats, carbohydrates are a valuable macronutrient for dogs that is needed to provide energy and help the body function. With aging, it is known that dogs lose lean body mass and gain fat mass [15]. Moreover, their energy requirements to maintain the body mass and function decreases [8]. In this study, we tested not only an experimental dog breed (Beagle) but also the most common small dog breeds (Maltese and Poodle). In particular, NFE digestibility was found to be related with age in Beagles, and the digestibility of crude fat was also affected by low moisture content and age in small breed dogs. Crude fat is the main energy source along with carbohydrates and proteins in dog foods. Therefore, it should be considered the higher possibility that the crude fat and NFE may contribute to the body weight gain in dogs with aging. This finding can be a useful information to determine the nutrient content for age-adequate diets for dogs.

\section{REFERENCES}

1. Hayek MG, Davenport GM. Nutrition and aging in companion animals. J Anti-Aging Med. 1998;1:117-23. https://doi.org/10.1089/rej.1.1998.1.117

2. Fahey GC Jr, Barry KA, Swanson KS. Age-related changes in nutrient utilization by companion animals. Annu Rev Nutr. 2008;28:425-45. https://doi.org/10.1146/annurev. nutr.28.061807.155325

3. Schauf S, Stockman J, Haydock R, Eyre R, Fortener L, Park JS, et al. Healthy ageing is asso- 
ciated with preserved or enhanced nutrient and mineral apparent digestibility in dogs and cats fed commercially relevant extruded diets. Animals. 2021;11:2127. https://doi.org/10.3390/ ani11072127

4. Food and Agriculture Organization of the United Nations, World Health Organization. Energy and protein requirements: Report of joint FAO/WHO Ad Hoc expert committee. Geneva: FAO and WHO; 1973. Report No.: FAO Nutrition Meetings Report Series No.: 52; WHO Technical Report Series No.: 522.

5. Kienzle E, Rainbird A. Maintenance energy requirement of dogs: what is the correct value for the calculation of metabolic body weight in dogs? J Nutr. 1991;121:S39-40. https://doi. org/10.1093/jn/121.suppl_11.S39

6. Bermingham EN, Thomas DG, Cave NJ, Morris PJ, Butterwick RF, German AJ. Energy requirements of adult dogs: a meta-analysis. PLOS ONE. 2014;9:e109681. https://doi. org/10.1371/journal.pone.0109681

7. Finke MD. Evaluation of the energy requirements of adult kennel dogs.J Nutr. 1991;121:S228. https://doi.org/10.1093/jn/121.suppl_11.S22

8. Harper EJ. Changing perspectives on aging and energy requirements: aging and energy intakes in humans, dogs and cats. J Nutr. 1998;128:2623S-6S. https://doi.org/10.1093/ jn/128.12.2623S

9. Harper EJ. Changing perspectives on aging and energy requirements: aging and digestive function in humans, dogs and cats. J Nutr. 1998;128:2632S-5S. https://doi.org/10.1093/ jn/128.12.2632S

10. de Brito CBM, Félix AP, de Jesus RM, de França MI, de Oliveira SG, Krabbe EL, et al. Digestibility and palatability of dog foods containing different moisture levels, and the inclusion of a mould inhibitor. Anim Feed Sci Technol. 2010;159:150-5. https://doi.org/10.1016/j.anifeedsci.2010.06.001

11. Analytical Research Cognizance. 2020-2029 Report on global pet food market by player, region, type, application and sales channel. Maharashtra: Analytical Research Cognizance; 2020. Report No.: 1478120.

12. Hilton J. Carbohydrates in the nutrition of the dog. Can Vet J.1990;31:128-9.

13. Fortes CMLS, Carciofi AC, Sakomura NK, Kawauchi IM, Vasconcellos RS. Digestibility and metabolizable energy of some carbohydrate sources for dogs. Anim Feed Sci Technol. 2010;156:121-5. https://doi.org/10.1016/j.anifeedsci.2010.01.009

14. Bosch G, Hagen-Plantinga EA, Hendriks WH. Dietary nutrient profiles of wild wolves: insights for optimal dog nutrition? Br J Nutr. 2015;113:S40-54. https://doi.org/10.1017/ S0007114514002311

15. Bellows J, Colitz CMH, Daristotle L, Ingram DK, Lepine A, Marks SL, et al. Common physical and functional changes associated with aging in dogs. J Am Vet Med Assoc. 2015;246:6775. https://doi.org/10.2460/javma.246.1.67 